\title{
O ambiente escolar incapaz de assegurar a saúde mental do professor: uma revisão literária
}

\author{
The school environment unable to ensure the teacher's mental health: a literary review \\ El entorno escolar no puede garantizar la salud mental del profesor: una revisión literaria
}

Lázaro Saluci Ramos $^{1 *}$, Regina Celia Monteiro ${ }^{2}$, Marcos Lopes Spinola ${ }^{2}$, Patricia de Cerqueira Pretti2 , Rozana Paz Martins Marvila², Cíntia Pancieri², Dara Ribeiro Ramos², Rosiane Ferreira Paz Oliveira², Adriana Rocha Furtunato do Espírito Santo², Tasmânia da Silva Oliveira Mantiolhe².

\section{RESUMO}

Objetivo: O objetivo desta revisão é reunir estudos e produções literárias que abordem a saúde mental do professor brasileiro que é constantemente violada pela incapacidade do Estado em oferecer segurança e condições dignas de trabalho. Revisão Bibliográfica: A saúde mental do docente interfere diretamente no objetivo principal da educação pública. Há que considerar o problema social de saúde pública que foi criado quando o Estado ofereceu um ambiente completamente abusivo e impróprio para que uma das maiores classes trabalhistas do País fosse encaixada. Dentre os fatores que desencadeiam transtornos psicológicos nos professores da rede pública nacional, o principal é a falta de estrutura para atender as exigências do plano educacional proposto. A remuneração é um dos fatores que mais causam desestímulo, já que no capitalismo, ter condições de arcar com os gastos é motivo de mente sã, o que não é dado aos docentes da rede pública brasileira. Considerações finais: $O$ desprezo pelas políticas públicas de saúde que atendam os professores se dá ao descaso que os entes da República, hiper remunerados, dão a classes trabalhistas amplas.

Palavras-chave: Saúde mental, Saúde do professor, Educação e saúde.

\begin{abstract}
Objective: The purpose of this review is to bring together studies and literary productions that address the mental health of the Brazilian teacher who is constantly violated by the State's inability to offer security and decent working conditions. Bibliographic Review: The teacher's mental health directly interferes with the main objective of public education. It is necessary to consider the social problem of public health that was created when the State offered a completely abusive and inappropriate environment for one of the largest labor classes in the country to be placed. Among the factors that trigger psychological disorders in teachers of the national public network, the main one is the lack of structure to meet the requirements of the proposed educational plan. Remuneration is one of the factors that most discourage, since in capitalism, being able to afford expenses is a reason for a healthy mind, which is not given to teachers in the Brazilian public system. Final considerations: The contempt for public health policies that serve teachers is due to the contempt that the overpaid entities of the Republic give to broad working classes.
\end{abstract}

Keywords: Mental health, Teacher health, Education and health.

\footnotetext{
${ }^{1}$ Faculdade Multivix (MULTIVIX), Cachoeiro de Itapemirim - ES.

*E-mail: lazaro321123@gmail.com

2 Faculdade Vale do Cricaré (FVC), São Mateus - ES.
} 


\section{RESUMEN}

Objetivo: El propósito de esta revisión es reunir estudios y producciones literarias que aborden la salud mental del maestro brasileño que es constantemente violado por la incapacidad del Estado para ofrecer seguridad y condiciones de trabajo dignas. Revisión bibliográfica: La salud mental del profesor interfiere directamente con el objetivo principal de la educación pública. Es necesario considerar el problema social de salud pública que se creó cuando el Estado ofreció un ambiente completamente abusivo e inapropiado para que se ubicara a una de las clases trabajadoras más grandes del país. Entre los factores que desencadenan trastornos psicológicos en los docentes de la red pública nacional, el principal es la falta de estructura para cumplir con los requisitos del plan educativo propuesto. La remuneración es uno de los factores que más desalientan, ya que en el capitalismo, poder pagar los gastos es una razón para una mente sana, que no se da a los maestros en el sistema público brasileño. Consideraciones finales: El desprecio por las políticas de salud pública que sirven a los maestros se debe al desprecio que las entidades pagadas en exceso de la República dan a las clases trabajadoras amplias.

Palabras clave: Salud mental, Salud docente, Educación y salud.

\section{INTRODUÇÃO}

A educação pública brasileira é cercada de problemas estruturais que desencadeiam constantes transtornos, tanto aos discentes quando ao corpo docente. Pouco foi abordada no decorrer dos anos a saúde mental do professor, haja vista que nas últimas décadas o contingente de alunos quadriplicou e o corpo docente sequer dobrou. Cada aluno reserva particularidades que podem influenciar no desenvolvimento escolar, o professor é o ator que precisa decifrar algumas dessas particularidades para alcançar o objetivo do ensino (DIEHL L e MARIN AH, 2016).

Inalcançado o objetivo central, há de se buscar o motivo pelo qual ele não foi atingido. A Organização Internacional do Trabalho (OIT) classifica a profissão do professor como uma das mais estressantes que existem no planeta. Posto isto, todas as enfermidades causadas pelo estresse entram na rota dos professores, tornando a classe ainda mais vulnerável. A depressão é a doença mais comum entre os professores que sofrem com o desgaste das salas de aula, pois situações como apatia, estresse, desânimo e desesperança, são os primeiros sinais de que a profissão já não está agradável, e são os principais causadores da doença (DIEHL L e MARIN AH, 2016).

O professor, assim como qualquer integrante de outra classe, é um ser humano, e está vulnerável as mesmas situações que qualquer outra pessoa no cotidiano. Naturalizar o sofrimento do docente como consequência da escolha da função é agir com desumanidade e dar vez ao desconhecimento. Durante muito tempo no Brasil, a função de docente da educação básica era mais comum entre mulheres, e na grande maioria das vezes mulheres pobres, cujo, a família necessitava de uma renda extra.

As mulheres de famílias ricas do início do século passado eram conservadas no lar, e o bom casamento era o maior objetivo, não a vida acadêmica. No decorrer dos anos, tornar-se professor se transformou em uma saída para quem não tinha condições de arcar com cursos superiores que davam acesso a cargos de maiores salários. Isso fez com que a profissão fosse classificada de "baixa renda", e quanto mais professores surgiam, devido aos menores empecilhos financeiros para sua formação, menores foram os salários (PENTEADO RZ e NETO SS, 2019).

A resolução do problema perpassa por inúmeros fatores, mas o principal deles está alocado no campo da estrutura do ambiente escolar. A estrutura curricular por exemplo, apresenta inúmeras obrigações ao professor que estão além do alcance do mesmo. Em quase todo Brasil a sala de aula contempla a figura de um único professor sem nenhum auxiliar e vários alunos. Salas de aula que comportam mais de trinta alunos se tornam um grande problema, não apenas para o aprendizado, mas para a saúde do docente que terá que lidar com várias individualidades e desenvolver um método que desperte o interesse da maioria (ARAÚJO TM, et al., 2019). 
A escola, além de não aportar corpo docente suficiente para atender as necessidades dos alunos, não disponibiliza a menor estrutura capaz de atender qualquer membro daquele ambiente no que diz respeito a saúde física e mental. São escassas as parcerias entre escola e saúde pública que vislumbrem este objetivo e nenhuma política pública nacional voltada a saúde mental do professor. Nenhuma política pública que priorize os cuidados médicos necessários que um professor deve ter, muito pelo contrário, a jornada de trabalho do professor além de ser maior, quase nunca permite o profissional de executar exames ou fazer consultas de rotina (ARAÚJO TM, et al., 2019).

A presente revisão objetiva reunir importantes estudos que apontem soluções para o problema da saúde do professor. A saúde pública brasileira quase não se concentra em estudar soluções para atender esta classe profissional que atua nos três turnos diários e em algumas situações, nos finais de semana. A remuneração do docente da educação básica no Brasil não alcança minimamente os valores necessários para suprir os enormes desgastes que o ambiente conturbado e desumanizado pode gerar ao profissional. É traçada, portanto, a meta de reunir ideias que foquem na solução dos problemas educacionais referentes a temática do exame de revisão proposto.

\section{REVISÃO BIBLIOGRÁFICA}

O ambiente escolar brasileiro se desenvolveu sob as necessidades das classes mais altas, classes estas que tinham condições de arcar com os custos de um filho na escola, além de não depender da mão de obra daquele ente familiar para a subsistência.

Durante este período, predominou a figura do professor como pessoa a ser respeitada pela sociedade, já que a demanda era escassa e a qualidade do ensino tinha mais condições de ser aperfeiçoada. Pouco se falou a democratização do ensino até o início do século XX, menos ainda se falou de saúde pública ou saúde mental de qualquer cidadão. $O$ zelo por estes campos era inalcançado devido ao baixo desenvolvimento tecnológico (PENTEADO RZ e NETO SS, 2019).

Com o advento das teorias que tratavam a educação como direito básico e propunham a democratização do acesso a educação, iniciou-se um novo período na era educacional no Brasil. Pensadores como Paulo Freire e Lev Semyonovich Vygotsky vincularam o desenvolvimento social interligado ao desenvolvimento educacional. Classes não tão baixas da época começaram a ter acesso a educação que passou a ser em partes pública. Nos arredores do século XXI os projetos educacionais passaram a incluir todas as classes, e através do acesso a educação buscou-se combater mais que 0 analfabetismo, mas a fome e a desigualdade social (CARVALHO JSF, 2007).

O aumento do número de alunos nas escolas solucionou o problema do acesso a educação, mas gerou problemas relacionados as estruturas físicas dos colégios e também ligados ao despreparo do ambiente escolar em assegurar a integridade física e mental do professor. Com o aumento do número de alunos, aumentou-se consideravelmente as individualidades humanas dividindo o mesmo espaço. Assim tratado por tempos, o professor foi eleito a ser a autoridade dentro da sala de aula, mas uma autoridade precisa ter técnicas e táticas que visem assegurar a ordem e o bom andamento na busca pelos objetivos (CARVALHO JSF, 2007).

Incapacitado para lidar com situações completamente abusivas e que ultrapassaram os limites humanos, o professor foi esquecido até adoecer. Casos de professores que adquiriram transtornos e que não conseguiram se reaproximar das salas de aula foram se tornando comuns. Traumas de diferentes formas foram identificados, como crises de pânico, choro e até desmaios.

Cenas do cotidiano brasileiro, onde alunos agridem professores ou até mesmo a exaustão e o desgaste, potencializaram a decadência disparada da qualidade e da segurança do ambiente de ensino. Os alunos foram despejados no ambiente escolar e as deficiências daquele ambiente despreparado foram despejadas sobre o professor. A função do professor, devido a isto passou a ser desumanizada, afastando possíveis profissionais que fariam a diferença, tornando a profissão indesejada e taxada de nociva a saúde (FACCI MGD, 2019) 
Envolver educação e saúde se tornou um meio eficaz para construir um ambiente educacional mais acessível e imponente (FALKENNERG MB, et al., 2014). A construção científica no ambiente escolar rende muitos profissionais capacitados para as áreas de maiores demandas na sociedade. Oportunizar caminhos para novas grandes mentes sempre foi um caminho para solucionar problemas sociais graves (BASSOLI F, 2014).

Um dos resultados da marginalização da função do professor foi apontado em recentes pesquisas pelo mundo mostrando que o professor é um dos servidores públicos que mais abandonam o cargo. O principal motivo se dá pelas prejudicialidades da função a saúde, e o outro motivo são as baixas remunerações. Ambos os problemas se encontram interligados quando é possível aferir que as pressões do capitalismo selvagem são capazes de adoecer o ser humano. A falta de recursos suficientes além da incapacidade de atender os padrões de felicidade estabelecidos pelo mercado são as raízes do adoecimento devido a baixa remuneração (TOSTES MV, et al., 2018).

Buscar responsáveis para esta anomalia não é uma tarefa muito difícil, pois os alunos já chegam ao ambiente escolar com os vícios que se tornam problemas em classe. A agressividade, indisciplina comportamental dentre tantas não colaborações necessárias para o bom andamento do ensino, são inseridos no cotidiano do aluno.

O ambiente que produz o ser humano, principalmente as periferias brasileiras, são o exemplo que eles levam para a vida. Todavia, o objetivo é solucionar o problema e não apontar culpados apenas. A solução perpassa também pela educação, já que o ambiente escolar é capaz de mudar traços da realidade e se inserir na vida do discente como uma nova realidade (SILVA APF, 2006).

\section{Políticas públicas para a saúde do professor}

As políticas públicas sempre foram o caminho mais coeso na solução de problemas sociais que ultrapassam os esforços simples. Na história da humanidade, nem sempre a forma mais simples ou clara foi suficiente para garantir qualidade de vida e existência (SOUZA C, 2006). Solucionar um problema social grave requer a inserção de políticas públicas. Existem programas no âmbito federal, estadual e municipal que visam atender a demanda da saúde do trabalhador.

A ideia é garantir que a classe seja incentivada a procurar cuidados, disponibilizando atendimento em horários diferentes do trabalho. Entretanto, o professor requer um pouco mais de cuidado, já que a carga horária de muitos cobre os três turnos do dia. Nenhuma política nesse sentido foi incentivada visando garantir o direito do professor de cuidar da própria saúde (SANTANA FAL e NEVES IR, 2017).

Quando o docente da educação pública brasileira necessita de tempo para cuidar da própria saúde, ele enfrenta uma série de burocracias, mais um desgaste que acaba desestimulando o professor a buscar os cuidados necessários.

$\mathrm{O}$ ambiente escolar também falha em oferecer aporte, geralmente o professor precisa contratar um substituto para ter cuidados rotineiros. A justificativa sai tão custosa, que as vezes é preferível buscar meios onerosos menos desgastantes, mesmo a lei trabalhista garantindo que o trabalhador pode se afastar para cuidados médicos (SANTANA FAL e NEVES IR, 2017). A lei diz o seguinte:

"Art. 473 - O empregado poderá deixar de comparecer ao serviço sem prejuízo do salário: ... IV - por um dia, em cada 12 meses de trabalho, em caso de doação voluntária de sangue devidamente comprovada; ... X - até 2 (dois) dias para acompanhar consultas médicas e exames complementares durante o período de gravidez de sua esposa ou companheira; XI - por 1 (um) dia por ano para acompanhar filho de até 6 (seis) anos em consulta médica; XII - até 3 (três) dias, em cada 12 (doze) meses de trabalho, em caso de realização de exames preventivos de câncer devidamente comprovada (BRASIL, 1943)."

Um grande projeto nacional voltado a saúde do professor pode despertar para as necessidades reais de inserir dentro da escola um corpo de apoio especialista em saúde docente. A especialização ainda não passa de um projeto, mas já é uma realidade muito palpável. Além da saúde mental, o professor necessita de 
cuidados físicos, como por exemplo a voz, as mãos devido aos movimentos da escrita em lousas, e até mesmo com os outros membros do corpo, já que ficam em constante movimento durante a realização das aulas. Estudos voltados a reduzir a sobrecarga nas salas de aula, devem ser realizados para que recomendações sejam feitas aos órgãos públicos responsáveis pelo organizacional da educação brasileira (ARAÚJO TM, et al., 2019).

Inserir uma política específica é o mesmo que tornar a saúde do docente um objetivo direto da saúde brasileira. Campanhas nacionais voltadas a saúde da mulher, saúde do homem e da criança, podem ser utilizados como exemplo. Até mesmo um mês específico voltado a saúde do professor seria uma campanha louvável e de grande repercussão. Se o professor vai bem a educação também ganha com isso, pois a transmissão do conhecimento depende da saúde física e mental. É de se estranhar que a classe ainda não tenha conquistado direitos expressivos com relação a saúde pública mesmo sendo tão grande, contudo, há de se considerar a falta de tempo devido as largas jornadas de trabalho necessárias para conquistar um salário digno (GOUVÊA LAVN, 2016).

Geralmente na rede pública de ensino, o professor tem o dia da semana para realizar o planejamento. $\bigcirc$ tempo do planejamento muitas vezes excede o necessário e o docente precisa ficar dentro do prédio escolar. Uma outra maneira de garantir que o professor tenha condições de cuidar preventivamente da saúde seria permitindo a ausência do profissional uma vez ao mês na data do planejamento. Os planejamentos são dias em que os docentes não entram em sala de aula, eles ficam desenvolvendo o projeto a ser aplicado em sala de aula em um local reservado na escola (SCARINCI AL e PACCA JLA, 2015).

A ideia central está sempre focada na prevenção. Valorizar para dignificar deveria ser o lema das políticas de saúde pública dos professores. A construção de pontes entre saúde e educação apresenta resultados positivos, principalmente quando a política está voltada ao combate e a instrução de doenças. Tornar o ambiente escolar mais saudável para o professor passa despercebido aos olhos do poder público, já que se trata também de uma classe trabalhista, porém com sérias limitações que faz com que não esteja nas mesmas condições das demais (GOUVÊA LAVN, 2016).

\section{A valorização salarial promovendo a saúde do profissional}

A remuneração é constantemente discutida nos grupos profissionais mais distintos. Nos círculos e debates acerca de salário e valorização profissional, o que mais sensibiliza a opinião pública é a remuneração do professor. A sociedade brasileira já reconhece a educação como principal instrumento de mudança e desenvolvimento social, dado isto, ter profissionais capacitados, satisfeitos e incentivados a promover uma educação de qualidade interessa diretamente a sociedade. Mas também é fácil identificar as dificuldades que as classes trabalhistas maiores encontram em conquistar valorização salarial. Se tratando da educação como bem público e direito de todos, as massas dos professores são servidores públicos e precisam lidar com uma construção abusiva de horas-aula para conquistar uma remuneração mais próxima da desejada e ainda sim bem distante da justa (FERNANDES MDE, et al., 2018).

O acúmulo de problemas dificulta a resolução dos mesmos. Acumular uma jornada exaustiva, uma má remuneração além das dificuldades comportamentais dos alunos, faz com os professores tenham mais desgaste em se manter na profissão do que exercendo ela de fato. O comprometimento da saúde mental do professor devido a aglomeração de situações indesejadas se torna comum diante dos fatos. Se algum desses problemas depende do professor para ser resolvido, ele fica com sua resolução cada vez mais distante, já que os problemas que não dependem do professor para sua resolução, ocupam ainda mais os "espaços" (SOUZA AN e LEITE MP, 2011).

O capitalismo exacerbado é um produtor de problemas de saúde, já que tudo que se necessita tem um preço. O trabalho em excesso na grande maioria das vezes é o maior causador de adoecimentos. A distopia encontrada no caso é trabalhar e adoecer para ter condições de envelhecer e arcar com os gastos de tratamentos de doenças que foram adquiridas em decorrência do trabalho. O mais estarrecedor disso tudo é que bem pouco do esforço empregado pelo trabalhador é revertido em benefícios para o próprio, mesmo assim a sociedade aceita com naturalidade, já que a construção histórica do capitalismo para domar as classes mais baixas, foi bem-sucedida (ANTUNES R e PRAUN L, 2015). 
Os estigmas construídos pelo mercado para incentivar a sociedade a consumir, é a máquina que move a desigualdade. Não conseguir atender os padrões sociais é sinal de insatisfação, e a insatisfação também gera adoecimento, já que a pessoa influenciada pela propaganda consumerista só estará feliz se conseguir galgar os injustos degraus sociais. O problema se torna uma roda gigante, motivando o início de ciclos depressivos até suicídios, fazendo com que o trabalhador nunca se sinta bom o suficiente para alcançar os falsos padrões, que foram criados apenas para que o almejassem e nunca para que o trabalhador $o$ alcance (ANTUNES $R$ e PRAUN L, 2015).

Compreende-se melhor o motivo do adoecimento dos professores estar ligado a baixa remuneração. Além de lidar com a agressividade das salas de aula, também precisa lidar com as frustrações sociais. Por alguns momentos parece que o professor não é tratado como ser humano, pois pouco é considerado os seus desejos, vícios, almejos em geral. É muito comum que seja cobrado do professor a educação moral, educação que não cabe ao docente transmitir, mas deve partir do âmbito familiar. $O$ acúmulo de funções extras constrói uma espécie de roda explorativa (PENTEADO RZ e NETO SS, 2019).

Os inúmeros fatores responsáveis pelo adoecimento do profissional, compreende a baixa remuneração como um dos principais. O desgaste físico e psicológico, como dores no corpo, mente cansada e baixa disposição, são problemáticas pouco discutidas no âmbito laboral. A remuneração tende a ser mais baixa quando a função necessita de mais demanda de trabalhadores. Isso se aplica principalmente a funções onde o emprego de mão de obra braçal é necessário (FERNANDES, MA, et al., 2018)

No Brasil, a valorização salarial do professor acontece a passos curtos e lentos, contudo, um estado se destacou nos últimos anos, superando mais que o dobro da média salarial nacional. $O$ estado do Maranhão no ano de 2020 vai pagar ao profissional que alcance 40 horas-aula $R \$ 6.358,96$. Não somente para os professores efetivos, mas aqueles que não possuem estabilidade e passam anualmente por processos seletivos.

A média Nacional do salário do professor da educação pública é de $R \$ 2.886,24$, muito abaixo do teto maranhense. A medida foi possível já que o governador tomou a decisão de repassar todo recurso do Fundo de Manutenção e Desenvolvimento da Educação Básica (FUNDEB) para a folha salarial e ainda complementar com recursos próprios do estado. O reajuste varia de $5 \%$ a $17,5 \%$, ou seja, todos acima da inflação do ano anterior que foi de 4,25\% (VERMELHO, 2020).

Compreende-se a escassez de verba pública para tornar a remuneração do professor mais justa e atrativa, porém, cargos que sustentam supersalários e podem ter quebra de remuneração, além do não cumprimento da exigência constitucional de cobrar a alíquota sobre as grandes fortunas e a não taxação dos lucros e dividendos para seguir o exemplo da maioria dos Países, deixam a folha do Estado inflada e impossibilitada de sustentar uma remuneração maior aos docentes da rede pública.

Enquanto o professor não tiver minimamente prioridade, com base na ideia de que a educação é a porta de saída para todos os problemas sociais, a realidade desastrosa, abusiva e marginalizada da educação básica brasileira, não encontrará uma solução, e o ambiente escolar permanecerá incapaz de assegurar a saúde do professor (EXAME, 2019).

\section{CONSIDERAÇÕES FINAIS}

Conclui-se, portanto, que os objetivos traçados para humanizar o ambiente escolar e garantir a saúde mental do professor, perpassam por políticas públicas de efeito, que garantam investimento público, campanhas de incentivo, valorização profissional e salarial. Uma jornada de trabalho mais digna e que permita ao profissional ter tempo para realizar averiguações rotineiras de saúde e tomar medidas de prevenção. Valorização do salário como forma de atender as necessidades financeiras e suprir os desgastes da profissão, que atualmente expõem o profissional a danos desde a saúde física até a saúde mental. Só é possível construir uma sociedade livre de desigualdades e rica em satisfação, com igualdade de oportunidades. E essas oportunidades só nascem quando a educação é plena, e para a educação ser plena todos os atores da vida escolar precisam estar saudáveis. 


\section{REFERÊNCIAS}

1. ANTUNES R, PRAUN L. A sociedade dos adoecimentos no trabalho. Serv. Soc. Soc, 2015; $123(4)$ : $407-427$.

2. ARAÚJO TM, et al. Trabalho e saúde de professoras e professores no Brasil: reflexões sobre trajetórias das investigações, avanços e desafios. Cad. Saúde Pública, 2019; 74: 55-80.

3. BASSOLI F. Atividades práticas e o ensino-aprendizagem de ciência(s): mitos, tendências e distorções. Ciênc.Educ., Bauru, 2014; 20(3): 579-593.

4. BRASIL. Consolidação das Leis do Trabalho. Rio de Janeiro: Abril, 1987; 118p.

5. CARVALHO JSF. A qualidade de ensino vinculada à democratização do acesso à escola. Estudos Avançados, 2007; 21(60): 307-310.

6. DIEHL L, MARIN AH. Adoecimento mental em professores brasileiros: revisão sistemática da literatura. Estudos Interdisciplinares em Psicologia, 2016; 7(2): 64-85.

7. EXAME. 2019. In: Reforma tributária deveria mirar em renda, patrimônio e grandes fortunas?. São Paulo: Economia. https://exame.abril.com.br/economia/reforma-tributaria-deveria-mirar-em-renda-patrimonio-e-grandes-fortunas/ Acesso em: 10 mar. 2020.

8. FACCI MGD. O adoecimento do professor frente à violência na escola. Fractal: Revista de Psicologia, 2019; 31 (2): 130-142.

9. FALKENBERG MB, et al. Educação em saúde e educação na saúde: conceitos e implicações para a saúde coletiva. Ciência \& Saúde Coletiva, 2014; 19(3): 847-852.

10. FERNANDES MA, et al. Transtornos mentais associados ao trabalho em profissionais de enfermagem: uma revisão integrativa brasileira. Revista Brasileira de Medicina do Trabalho, 2018; 16(2): 218-224.

11. FERNANDES MDE, et al. Remuneração de professores de educação básica nos setores público e privado na esfera municipal. Educação \& Pesquisa, 2018; 44(2): 1-16.

12. GOUVÊA LAVN. As condições de trabalho e o adoecimento de professores na agenda de uma entidade syndical. Saúde Debate, 2016; 40(111): 206-219.

13. PENTEADO RZ, NETO SS. Mal-estar, sofrimento e adoecimento do professor: de narrativas do trabalho e da cultura docente à docência como profissão. Saúde e Sociedade, 2019; 11(1): 1-14.

14. SANTANA FAL, NEVES IR. Saúde do trabalhador em educação: a gestão da saúde de professores de escolas públicas brasileiras. Saúde Sociedade, 2017; 26(3): 786-797.

15. SCARINCI AL, PACCA JLA. O planejamento do ensino em um programa de desenvolvimento profissional docente. Educação em revista, 2015; 31(2): 253-279.

16. SILVA APF. A escola diante de alunos em situação de risco: um antídoto ou uma armadilha?. An. 1 Congr. Intern. Pedagogia Social. Disponível em: <http://www.proceedings.scielo.br/scielo.php?script=sci_arttext\&pid=MSC0000000092006000100003\&lng=en\&nrm= iso>. Acesso em: 10 de abr. 2020.

17. SOUZA AN, LEITE MP. Condições de trabalho e suas repercussões na saúde dos professores da educação básica no Brasil. Educação \& Sociedade, 2011; 117(32): 1105-1121.

18. SOUZA C. Políticas públicas: uma revisão da literature. Sociologias, 2006; 16(2): 20-45.

19. TOSTES MV, et al. Sofrimento mental de professores do ensino público. Saúde Debate, 2018; 42(116): 87-99.

20. VERMELHO. 2020. In: Flávio Dino anuncia salário de R\$ 6,3 mil para professores do Maranhão. São Paulo. Disponível em: https://vermelho.org.br/2020/02/03/flavio-dino-anuncia-salario-de-r-63-mil-para-professores-domaranhao/. Acesso em: 9 mar. 2020. 